Journal of
Nutrigenetics
Nutrigenomics
J Nutrigenet Nutrigenomics 2017;10:9-18

DOI: 10.1159/000455914

Received: May 24, 2016

Accepted: January 10, 2017

Published online: March 29, 2017 (c) 2017 S. Karger AG, Basel www.karger.com/jnn

\title{
Review
}

\section{Common Variants of Vitamin D Receptor Gene Polymorphisms and Susceptibility to Coronary Artery Disease: A Systematic Review and Meta-Analysis}

\author{
Shahab Alizadeh ${ }^{a} \quad K$ urosh Djafarian ${ }^{b}$ Hamzeh Alizadeh ${ }^{d}$ Reza Mohsenia \\ Sakineh Shab-Bidar ${ }^{\mathrm{c}}$ \\ a Students' Scientific Research Center (SSRC), and Departments of ${ }^{b}$ Clinical Nutrition and \\ ${ }^{c}$ Community Nutrition, School of Nutritional Sciences and Dietetics, Tehran University of \\ Medical Sciences (TUMS), Tehran, and d Genetics Research Center, Department of Genetics \\ and Breeding, The University of Guilan, Rasht, Iran
}

\section{Keywords}

Vitamin D receptor · Polymorphism · Coronary artery disease $\cdot$ Meta-analysis

\begin{abstract}
Background and Aims: ApaI, FokI, TaqI, and BsmI polymorphisms in the vitamin D receptor $(V D R)$ gene have been reported to be associated with the risk of coronary artery disease (CAD), although the results of previous studies have been inconsistent. The aim of this study was to explore whether these polymorphisms play a role in the genetic susceptibility to CAD. Methods: A comprehensive search of Medline and Embase databases was conducted for studies evaluating the association between the VDR polymorphisms and CAD risk. Odds ratios with $95 \%$ confidence intervals were calculated to assess the strength of association in the dominant model, recessive model, allelic model, and genotypes contrast. Results: Nine studies involving a total of 5,259 cases and 1,981 controls were finally included in this meta-analysis. Overall, no significant associations were found between ApaI, FokI, TaqI, and BsmI polymorphisms and the risk of CAD in any of the genetic models (all $p>0.05$ ). Moreover, a subgroup analysis by ethnicity did not reveal a significant relationship between any of the examined polymorphisms and CAD risk in Caucasians and East-Asians for any model (all $p>$ 0.05). Conclusion: Current evidence suggests that the ApaI, FokI, TaqI, and BsmI polymorphisms of the VDR gene might not be associated with genetic susceptibility to CAD. Further well-designed studies with large sample sizes are needed to confirm our results.
\end{abstract}


Alizadeh et al.: Common Variants of Vitamin D Receptor Gene Polymorphisms and Susceptibility to Coronary Artery Disease: A Systematic Review and Meta-Analysis

\section{Introduction}

Coronary artery disease (CAD) is the most prevalent cardiovascular disease [1] and is the major cause of morbidity and mortality worldwide [2,3]. CAD is caused by a thrombotic occlusion of coronary arteries triggered by atherosclerotic plaque disruption, resulting in an activation of coagulation processes [4]. It is a complex, multifactorial, and polygenic disorder that involves an interaction between genetic predisposition and environmental factors [5]. It has been shown that traditional risk factors, including diet, obesity, diabetes, hypertension, dyslipidemia, inflammation, smoking, and alcohol consumption, allow the prediction of only about $50 \%$ of the absolute risk of a cardiovascular event in individual patients [6, 7], and the remaining risk is attributed to genetic influences [8]. Genetic susceptibility may be caused by mutations and polymorphisms in a variety of genes mostly involved in blood coagulation, regulation of blood pressure, and metabolism of glucose, lipids, or homocysteine [7].

Various association studies have attempted to identify genetic variants that contribute to CAD; among them, the vitamin D receptor (VDR) gene has received special attention and has been reported as one of the possible candidates for cardiovascular disorders [9]. A recent meta-analysis demonstrated a linear, inverse association between circulating 25-hydroxyvitamin D and risk of cardiovascular disease [10]. The genomic effects of 1,25-dihydroxyvitamin D in a wide variety of tissues are mediated by VDR [11]. The VDR gene is located on the long arm of chromosome 12 (12q12-14) and consists of at least 5 promoter regions, 8 proteincoding exons, and 6 untranslated exons, which are alternatively spliced [11-13]. More than 470 VDR single-nucleotide polymorphisms have been determined so far; among them, FokI (rs2228570), ApaI (rs7975232), BsmI (rs1544410), and TaqI (rs731236) have been thoroughly studied for their effects on various physiological and pathological phenotypes, such as cancer, diabetes, myocardial infarction, and CAD [13-15].

Molecular epidemiological studies have presented seemingly contradictory results concerning a potential role of the VDR gene polymorphisms in CAD susceptibility. A single study may have low statistical power due to a small sample size and other limitations. Therefore, in order to decisively draw conclusions, the present meta-analysis was conducted to overcome the limitations of individual studies and to resolve these controversial results, as well as to decrease the uncertainty of the effect size of estimated risk.

\section{Materials and Methods}

\section{Publication Search}

All studies reporting on the association between the FokI, BsmI, TaqI, and ApaI polymorphisms of the $V D R$ gene and susceptibility to CAD published in English before January 2016 were identified by comprehensive computer-based searches of Medline and Embase databases. The following keywords were used for searching: (vitamin D receptor OR VDR) AND (polymorphism* OR variant* OR mutation) AND (cardiovascular diseases OR coronary artery disease OR coronary heart disease OR ischemic heart disease OR myocardial infarction OR angina). Google scholar and cross-references within both original and review articles were searched for additional literature. The search was restricted to articles in English.

\section{Inclusion Criteria}

Two investigators reviewed all identified studies independently to determine whether an individual study was eligible for inclusion. The selection criteria for studies to be considered for this meta-analysis were as follows: (1) assessing the FokI, BsmI, TaqI, and ApaI polymorphisms of the VDR gene and risk of CAD; (2) applying cohort studies, case-control studies, or nested case-control studies; (3) supplying the number of individual genotypes for the mentioned polymorphisms in cases and controls; and (4) appropriate CAD diagnosis criteria. Cross-sectional studies, reviews, case reports, and animal studies were excluded. Furthermore, studies were excluded if the information could not be extracted. 
Alizadeh et al.: Common Variants of Vitamin D Receptor Gene Polymorphisms and Susceptibility to Coronary Artery Disease: A Systematic Review and Meta-Analysis

Data Extraction and Quality Assessment

The following information was collected from each study: the authors' names, journal and year of publication, country of origin, ethnicity, gender, mean or range of age, sample size of cases and controls, and number of cases and controls for each genotype. Data were extracted independently by 2 investigators, and disagreements during the data extraction were resolved by discussion among all reviewers. Furthermore, the quality of the studies was assessed by the Newcastle-Ottawa Scale (NOS) [16]. This quality assessment tool judges studies on the basis of a star system, ranging from 0 to 9 stars and comprising the areas selection, comparability, and outcome. Reports scoring 7-9 were classified as "high quality."

\section{Statistical Analyses}

Deviation from Hardy-Weinberg equilibrium (HWE) for the distribution of the allele frequencies was analyzed by Fisher exact test in control groups [17]. Odds ratios (ORs) corresponding to a 95\% confidence interval (CI) were applied to evaluate the strength of association of VDR polymorphisms with CAD risk; ORs were calculated according to the method of Woolf [18]. The pooled ORs were performed for the dominant model, recessive model, allelic model, homozygote model, and heterozygote contrast, respectively. For each genetic contrast, a subgroup analysis according to ethnicity was applied to evaluate ethnicity-specific effects. Heterogeneity among the studies was assessed by the Cochran $\mathrm{Q}$ test and the $I^{2}$ statistic $\left(I^{2}=(\mathrm{Q}-\mathrm{df}) / \mathrm{Q} \times\right.$ $100 \% ; I^{2}<25 \%$, no heterogeneity; $I^{2}=25-50 \%$, moderate heterogeneity; $I^{2}=50-75 \%$, large heterogeneity; $I^{2}>75 \%$, extreme heterogeneity $[19,20]$. The heterogeneity was considered significant if either the $Q$ statistic had $p<0.1$ or if $I^{2}>50 \%$. When heterogeneity was considered significant, the random-effects model (DerSimonian-Laird approach) was applied. Otherwise, the fixed-effects model (Mantel-Haenszel approach) was applied [21, 22]. Begg's and Egger's [23] tests were performed to assess the publication bias of the studies. All statistical tests for this meta-analysis were performed with STATA software (version 14.0; Stata Corporation, College Station, TX, USA).

\section{Results}

\section{Studies' Characteristics}

A total of 281 studies were identified by the literature search. The flow diagram describing the process of screening and excluding articles for specific reasons is shown in Figure 1. Of the 272 excluded studies, 44 were duplicate publications; 196 were not relevant to VDR gene polymorphisms and CAD risk; 12 were reviews, editorials, or comments; 4 were case reports; 5 were studies that reported on the association between other polymorphisms of the VDR gene and CAD risk; 4 were on patients with diabetes or kidney disorders; 2 were studies without any control group; and 8 were other irrelevant articles. A total of 8 relevant studies (cases, 5,259; controls, 1,981) were finally included based on the inclusion criteria for CAD susceptibility related to the FokI, BsmI, TaqI, and ApaI polymorphisms [24-32]. Of these, 7 studies were performed in Caucasians [24-27, 29, 30, 32], and 2 studies [28, 31] were performed in East-Asians. Studies' characteristics are summarized in Table 1. Moreover, genotype and allele distributions for each study are shown in Table 2.

\section{Meta-Analysis of BsmI Polymorphism (rs1544410)}

There were 4 studies (cases, 2,574; controls, 1,297) concerning the BsmI polymorphism and CAD risk (Tables 1, 2). Of these, 3 studies were performed in Caucasian populations [24, $25,29]$, and 1 study was performed in East-Asians [31]. For this polymorphism, the study by Ortlepp et al. [25] deviated from HWE. In the overall population, when all eligible studies were pooled, the analysis revealed no significant association between the BsmI polymorphism and risk of CAD in all defined models, including the dominant model (OR $=1.02,95 \%$ $\mathrm{CI}=0.87-1.19)$, recessive model $(\mathrm{OR}=1.53,95 \% \mathrm{CI}=0.88-2.68)$, allelic model $(\mathrm{OR}=1.17$, $95 \% \mathrm{CI}=0.87-1.58)$, homozygote model ( $\mathrm{OR}=1.61,95 \% \mathrm{CI}=1.82-3.17)$, and heterozygote contrast (Aa vs. AA, OR =0.97, 95\% CI = 0.82-1.14) (Table 3). Subgroup analysis by ethnicity 


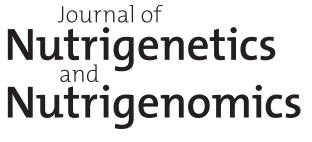

\begin{tabular}{l|l}
\hline J Nutrigenet Nutrigenomics 2017;10:9-18 \\
\hline DOI: 10.1159/000455914 & $\begin{array}{l}\text { C 2017 S. Karger AG, Basel } \\
\text { www.karger.com/jnn }\end{array}$ \\
\hline Alizadeh et al.: Common Variants of Vitamin D Receptor Gene Polymorphisms and
\end{tabular}

Alizadeh et al.: Common Variants of Vitamin D Receptor Gene Polymorphisms and
Susceptibility to Coronary Artery Disease: A Systematic Review and Meta-Analysis

Table 1. Characteristics of the studies included in the meta-analysis

\begin{tabular}{|c|c|c|c|c|c|c|c|c|c|}
\hline First author [ref.] & Year & Country & Ethnicity & Sex & $\begin{array}{l}\text { Cases/ } \\
\text { controls }\end{array}$ & Case/control age, years ${ }^{\mathrm{a}}$ & $\begin{array}{l}\text { Genotype } \\
\text { method }\end{array}$ & Polymorphism & $\begin{array}{l}\text { Quality } \\
\text { score }\end{array}$ \\
\hline Ortlepp [24] & 2001 & Germany & Caucasian & $\mathrm{M} / \mathrm{F}$ & $217 / 273$ & $61.5 \pm 9.9 / 61.5 \pm 9.9$ & PCR-RFLP & BsmI & 7 \\
\hline Ortlepp [25] & 2003 & Germany & Caucasian & $\mathrm{M} / \mathrm{F}$ & $2,087 / 775$ & $59.8 \pm 7.1 / 56 \cdot 5 \pm 11.2$ & PCR-RFLP & BsmI & 7 \\
\hline O’Halloran [27] & 2006 & Ireland & Caucasian & $\mathrm{M} / \mathrm{F}$ & $1,598 / 386$ & NR/NR & PCR-RFLP & ApaI, FokI & 7 \\
\hline Pan [31] & 2009 & China & Asian & $\mathrm{M} / \mathrm{F}$ & $152 / 212$ & $59.2 \pm 11.3 / 58.6 \pm 11.1$ & PCR-RFLP & FokI, BsmI & 8 \\
\hline Hossein-Nezhad [26] & 2014 & Iran & Caucasian & $\mathrm{M} / \mathrm{F}$ & $642 / 118$ & $57.93 \pm 16 / 57.46 \pm 10$ & PCR-RFLP & FokI & 6 \\
\hline Abu el Maaty [32] & 2016 & Egypt & Caucasian & $\mathrm{M}$ & $137 / 58$ & $35-50 / 35-50$ & PCR-RFLP & TaqI, ApaI & 8 \\
\hline He [28] & 2015 & China & Asian & $\mathrm{M} / \mathrm{F}$ & $215 / 67$ & $62.1 \pm 9.4 / 59.6 \pm 13.3$ & PCR-RFLP & Tru9I, ApaI, TaqI, FokI & 9 \\
\hline Garbuzova [29] & 2015 & Ukraine & Caucasian & $\mathrm{M} / \mathrm{F}$ & $118 / 234$ & $55.9 \pm 0.8 / 66.0 \pm 0.9$ & PCR-RFLP & ApaI, FokI , BsmI, TaqI & 8 \\
\hline
\end{tabular}

NR, not reported; PCR, polymerase chain reaction; RFLP, restriction fragment length polymorphism. ${ }^{\text {a }}$ Age is reported as mean \pm standard deviation or range.

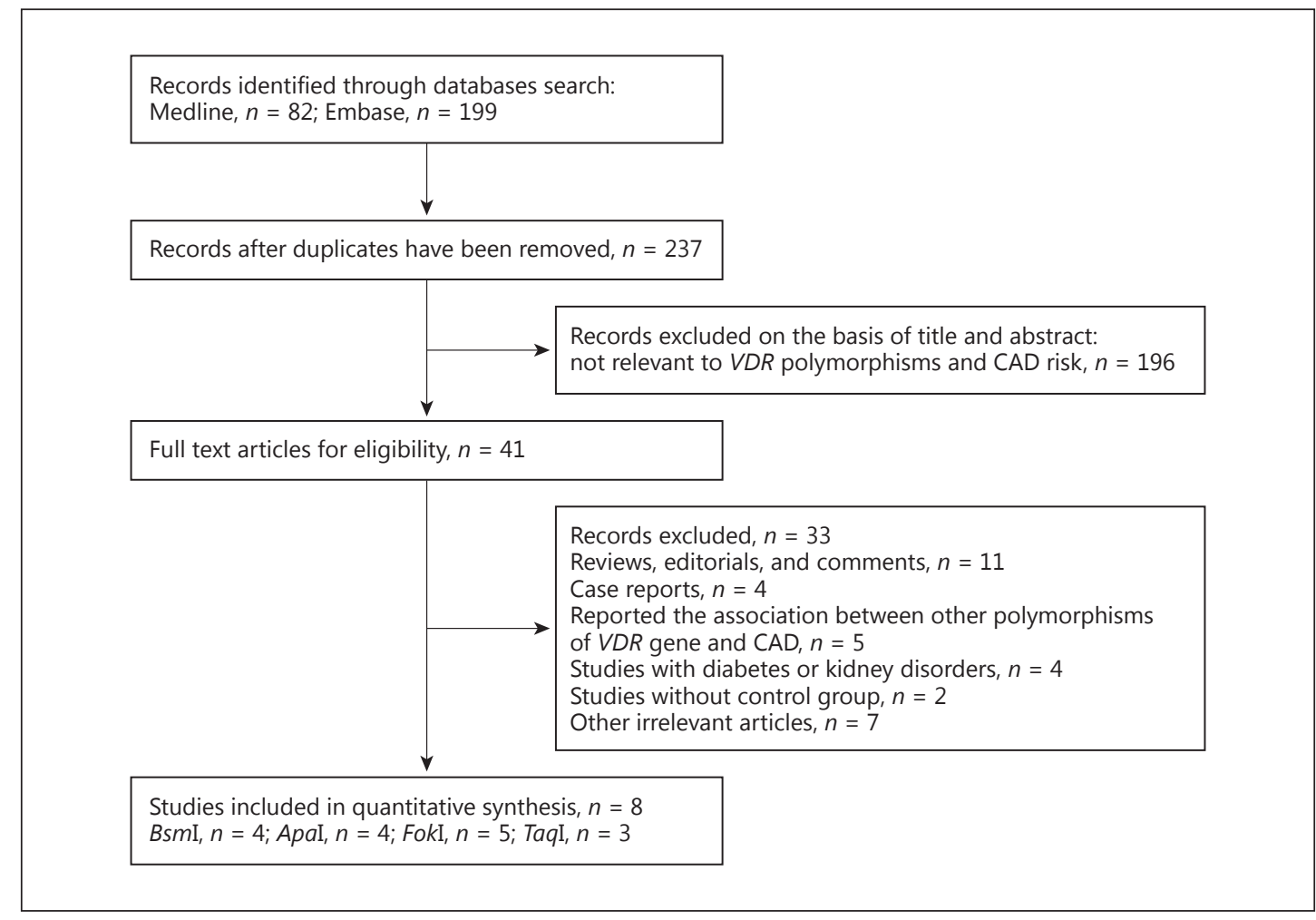

Fig. 1. Flow diagram describing the process of screening and excluded articles.

did not show a significant association between the BsmI polymorphism and CAD risk in Caucasians in any of the genetic models. Since there was only 1 study on an East-Asian population, a subgroup analysis by ethnicity could not be performed for this population.

\section{ApaI Polymorphism (rs7975232)}

Four studies including 2,068 cases and 745 controls addressed this issue [27-30] (Tables 1, 2). Of these, 3 studies were performed in Caucasians (cases, 1,853; controls, 678) [27, 29, 30], and 1 study was performed in East-Asians (cases, 215; controls, 67) [28]. The results of pooled ORs in different analysis models are shown in Table 3. No significant association was found between the ApaI polymorphism and the risk of CAD in the dominant model $(\mathrm{OR}=1.05$, $95 \% \mathrm{CI}=0.83-1.27)$, recessive model $(\mathrm{OR}=1.02,95 \% \mathrm{CI}=0.78-1.27)$, allelic model (OR $=$ 


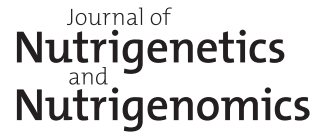

\begin{tabular}{l|l}
\hline J Nutrigenet Nutrigenomics 2017;10:9-18 \\
\hline DOI: 10.1159/000455914 & $\begin{array}{l}\text { (c) 2017 S. Karger AG, Basel } \\
\text { www.karger.com/jnn }\end{array}$ \\
\hline Alizadeh et al.: Common Variants of Vitamin D Receptor Gene Polymorphisms and
\end{tabular}

Table 2. Distribution of VDR genotypes and alleles in CAD patients and controls

\begin{tabular}{|c|c|c|c|c|c|c|c|c|c|c|c|c|}
\hline \multirow{2}{*}{$\begin{array}{l}\text { First author [ref.] } \\
\text { BsmI }\end{array}$} & \multicolumn{5}{|c|}{ CAD cases } & \multicolumn{5}{|c|}{ Healthy controls } & \multirow[t]{2}{*}{ P-HWE } & \multirow[t]{2}{*}{ MAF } \\
\hline & $\mathrm{bb}$ & $\mathrm{bB}$ & $\mathrm{BB}$ & $\mathrm{b}$ & B & $\mathrm{bb}$ & $\mathrm{bB}$ & $\mathrm{BB}$ & $\mathrm{b}$ & B & & \\
\hline Ortlepp [24] & 51 & 110 & 56 & 212 & 220 & 77 & 152 & 64 & 306 & 280 & 0.497 & 0.47 \\
\hline Ortlepp [25] & 643 & 1,093 & 351 & 2,379 & 2,186 & 232 & 419 & 124 & 883 & 667 & $0.004^{*}$ & 0.43 \\
\hline Pan [31] & 129 & 21 & 2 & 279 & 25 & 170 & 38 & 4 & 378 & 46 & 0.285 & 0.11 \\
\hline \multirow[t]{2}{*}{ Garbuzova [29] } & 44 & 52 & 22 & 140 & 104 & 105 & 104 & 25 & 314 & 154 & 0.92 & 033 \\
\hline & \multicolumn{5}{|c|}{ CAD cases } & \multicolumn{5}{|c|}{ Healthy controls } & \multirow[t]{2}{*}{ P-HWE } & \multirow[t]{2}{*}{ MAF } \\
\hline ApaI & $\mathrm{AA}$ & Aa & aа & A & $\mathrm{a}$ & AA & Aa & aа & A & $\mathrm{a}$ & & \\
\hline O’Halloran [27] & 443 & 797 & 358 & 1,683 & 1,513 & 109 & 195 & 82 & 413 & 359 & 0.767 & 0.46 \\
\hline Abu el Maaty [32] & 38 & 63 & 36 & 139 & 135 & 22 & 22 & 14 & 66 & 50 & 0.084 & 0.43 \\
\hline He [28] & 104 & 93 & 18 & 301 & 129 & 31 & 29 & 7 & 91 & 43 & 0.954 & 0.32 \\
\hline \multirow[t]{2}{*}{ Garbuzova [29] } & 34 & 58 & 26 & 126 & 110 & 77 & 102 & 55 & 256 & 212 & 0.065 & 0.45 \\
\hline & \multicolumn{5}{|c|}{ CAD cases } & \multicolumn{5}{|c|}{ Healthy controls } & \multirow[t]{2}{*}{ P-HWE } & \multirow[t]{2}{*}{ MAF } \\
\hline FokI & $\mathrm{FF}$ & $\mathrm{Ff}$ & $\mathrm{ff}$ & $\mathrm{F}$ & $\mathrm{f}$ & $\mathrm{FF}$ & $\mathrm{Ff}$ & $\mathrm{ff}$ & $\mathrm{F}$ & $\mathrm{f}$ & & \\
\hline O’Halloran [27] & 615 & 756 & 227 & 1,986 & 1,210 & 131 & 207 & 48 & 469 & 303 & $0.014^{*}$ & 0.39 \\
\hline Hossein-Nezhad [26] & 338 & 254 & 50 & 930 & 354 & 76 & 34 & 8 & 186 & 50 & 0.136 & 0.21 \\
\hline Pan [31] & 47 & 65 & 40 & 159 & 145 & 68 & 97 & 47 & 233 & 191 & 0.269 & 0.45 \\
\hline He [28] & 61 & 103 & 53 & 225 & 209 & 28 & 27 & 12 & 83 & 51 & 0.234 & 0.38 \\
\hline \multirow[t]{2}{*}{ Garbuzova [29] } & 32 & 61 & 25 & 125 & 111 & 67 & 115 & 52 & 249 & 219 & 0.841 & 0.47 \\
\hline & \multicolumn{5}{|c|}{ CAD cases } & \multicolumn{5}{|c|}{ Healthy controls } & \multirow[t]{2}{*}{ P-HWE } & \multirow[t]{2}{*}{ MAF } \\
\hline TaqI & TT & $\mathrm{TC}$ & CC & $\mathrm{T}$ & $\mathrm{C}$ & $\mathrm{TT}$ & $\mathrm{TC}$ & $\mathrm{CC}$ & $\mathrm{T}$ & $\mathrm{C}$ & & \\
\hline Abu el Maaty [32] & 36 & 60 & 41 & 132 & 142 & 18 & 27 & 13 & 63 & 53 & 0.636 & 0.46 \\
\hline $\mathrm{He}[28]$ & 195 & 20 & 0 & 410 & 20 & 63 & 4 & 0 & 130 & 4 & 0.801 & 0.03 \\
\hline Garbuzova [29] & 44 & 57 & 17 & 145 & 91 & 103 & 108 & 23 & 314 & 154 & 0.488 & 0.33 \\
\hline
\end{tabular}

CAD, coronary artery disease; P-HWE, $p$ value for Hardy-Weinberg equilibrium; MAF, minor allele frequency of control group. * Indicates statistical significance.

$1.03,95 \% \mathrm{CI}=0.90-1.17)$, homozygote model (OR $=1.06,95 \% \mathrm{CI}=0.75-1.37)$, and heterozygote contrast (Aa vs. AA, OR $=1.05,95 \% \mathrm{CI}=0.81-1.28$ ) in the overall population. Subgroup analysis by ethnicity did not show any significant association between ApaI polymorphism and CAD risk in Caucasians in any of the genetic models. Subgroup analysis by ethnicity could not be performed in East-Asians due to insufficient data.

\section{FokI Polymorphism (rs2228570)}

There were 6 studies [26-29,31,32] with 2,823 cases and 1,072 controls concerning the FokI polymorphism and CAD risk; among them, 4 studies were performed in Caucasians [26, 27, 29, 32], and 2 studies were performed in East-Asians [28, 31] (Tables 1, 2). For this polymorphism, the studies by O'Halloran et al. [27] and Abu el Maaty et al. [32] deviated from HWE. We did not find a statistically significant association between the FokI polymorphism and CAD risk under the dominant model $(\mathrm{OR}=0.91,95 \% \mathrm{CI}=0.75-1.07)$, recessive model $(\mathrm{OR}=1.08,95 \% \mathrm{CI}=0.86-1.35)$, allelic model (OR $=1.05,95 \% \mathrm{CI}=0.85-1.30)$, homozygote model (OR $=0.83,95 \% \mathrm{CI}=0.58-1.08)$, and heterozygote contrast $(\mathrm{TC}$ vs. TT, OR $=1.13,95 \%$ 


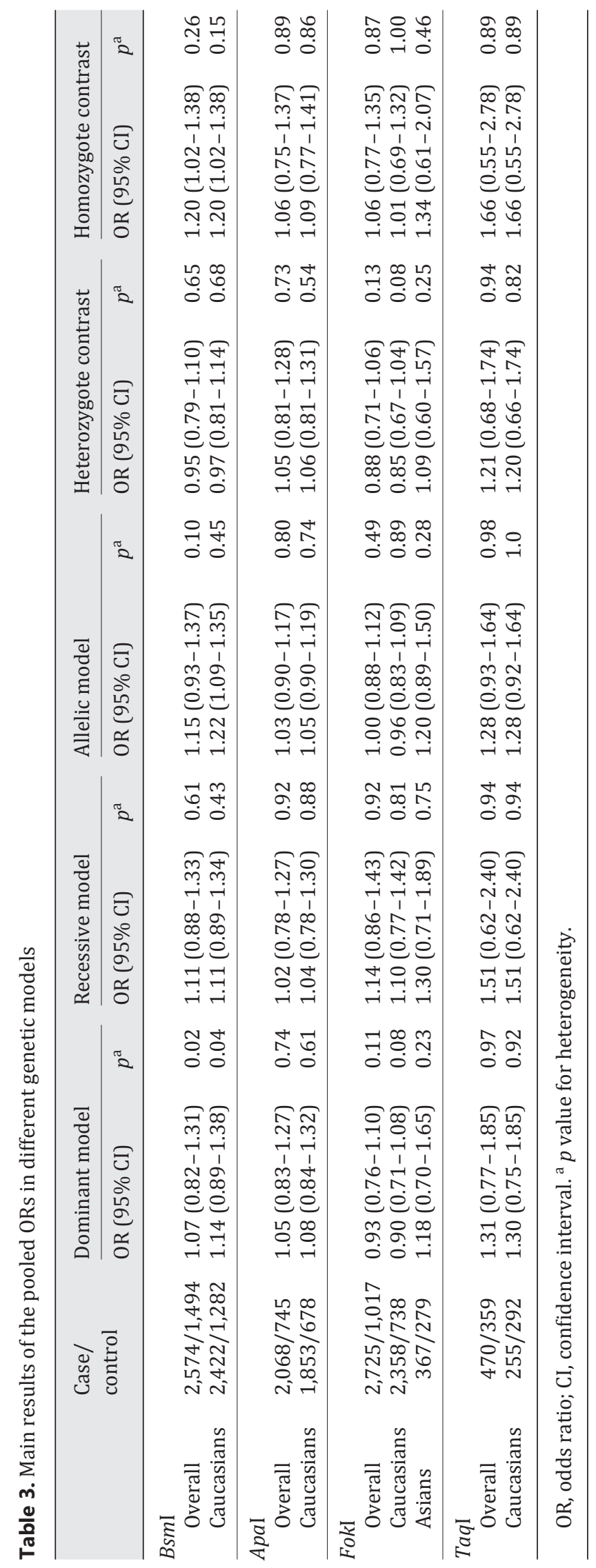


$\mathrm{CI}=0.83-1.55$ ) in the overall population (Table 3 ). We also did not find any association in the subgroup analysis of Caucasians and East-Asians in any of the genetic models.

TaqI Polymorphism (rs731236)

The TaqI polymorphism was investigated in 3 studies [28-30], including 470 cases and 359 controls; among them, 2 studies were performed in Caucasians [29, 30], and 1 study was performed in East-Asians [28] (Tables 1, 2). No significant association was found between this polymorphism and the risk of CAD in the dominant model $(\mathrm{OR}=1.31,95 \% \mathrm{CI}=0.77$ 1.85), recessive model ( $\mathrm{OR}=1.51,95 \% \mathrm{CI}=0.62-2.40)$, allelic model $(\mathrm{OR}=1.28,95 \% \mathrm{CI}=$ $0.93-1.64)$, homozygote model (OR $=1.66,95 \% \mathrm{CI}=0.91-3.03)$, and heterozygote contrast (Ff vs. FF, OR $=1.21,95 \% \mathrm{CI}=0.68-1.74$ ) in the overall population. Furthermore, no significant association was observed in the subgroup analysis of Caucasians in any of the genetic models (Table 3). We could not evaluate this polymorphism in East-Asians because there was only 1 study.

\section{Heterogeneity and Publication Bias}

Heterogeneity of the included studies is reported in Table 3. For the BsmI polymorphism, in the overall analysis, there was a significant moderate heterogeneity in the recessive $\left(I^{2}=\right.$ $54.1 \%, p=0.06)$, allelic $\left(I^{2}=71.6 \%, p=0.01\right)$, and homozygote $\left(I^{2}=65.9 \%, p=0.03\right)$ models. Moreover, a statistically significant heterogeneity was detected for FokI polymorphism in the dominant $\left(I^{2}=62.0 \%, p=0.02\right)$, allelic $\left(I^{2}=62.6 \%, p=0.02\right)$, and heterozygote $\left(I^{2}=56.3 \%\right.$, $p=0.04$ ) models. No significant heterogeneity was found in any of the other models in the overall analysis. Because the number of included studies for our meta-analysis was small, the test for publication bias was only conducted for the FokI polymorphism (including 6 studies). Begg's and Egger's tests found no evidence of a publication bias in any of the genetic models for the FokI polymorphism (data not shown).

\section{Sensitivity Analyses}

We removed the study by Ortlepp et al. [25], Abu el Maaty et al. [32], and O'Halloran et al. [27] in the meta-analysis due to the genotype distribution in the control groups, since BsmI and FokI polymorphisms deviated from HWE, respectively. We found that the corresponding pooled ORs were not substantially altered, which points to the reliability of our results.

\section{Discussion}

FokI, BsmI, TaqI, and ApaI polymorphisms in the VDR gene have been suggested as potential genetic factors for CAD susceptibility. However, the results from published studies are still inconclusive. Thus, the present meta-analysis was performed to comprehensively analyze these associations. The results of our meta-analysis do not provide evidence for an association between the VDR FokI, BsmI, TaqI, and ApaI polymorphisms and the risk of CAD. These findings suggest that these polymorphisms may not be involved in CAD pathogenesis and, thus, could not explain individual differences in genetic susceptibility to CAD. Since ethnic background can influence the results [33], we also conducted subgroup analyses by ethnicity for these polymorphisms but again found no relation in stratified analyses.

Consistent with our results, results of a recently published study with a Mendelian randomization design in the Copenhagen City Heart showed that there is no causal relationship between lower serum vitamin $\mathrm{D}$ and increased risk of ischemic heart disease or myocardial infarction, and the genetic variants were not associated with increased risk of ischemic heart disease [34]. 
In contrast to our results, in a cross-sectional study carried out by Ortlepp et al. [35] which covered 3,436 Caucasian subjects, the BB genotype of $V D R$ was significantly associated with the presence of myocardial infarction in patients below 65 years $(\mathrm{OR}=1.38,95 \% \mathrm{CI}=$ $1.07-1.79, p=0.016)$. Unlike in the study by Ortlepp et al. [35], in a study by Van Schooten et al. [36], a marginally significant association was found, which indicated a higher incidence of CAD in carriers of the bb allele pair of BsmI VDR (OR $=4.2,95 \% \mathrm{CI}=0.8-22.5, p=0.06)$. This study was carried out in 41 Caucasian patients with documented CAD. Moreover, the DIABHYCAR prospective cohort study [37], including 3,137 patients with type 2 diabetes, also demonstrated an increased risk for incident cases of CAD among carriers of the B allele (hazard ratio $=1.16,95 \% \mathrm{CI}=1.05-1.29, p=0.002$ ). Although the present meta-analysis did not find any associations between FokI, TaqI, BsmI, and ApaI polymorphisms of the VDR gene and the risk of CAD in the overall population, in Caucasians, and in Asians, the results should be interpreted with caution.

For an evaluation of the investigated polymorphisms, there were limited published studies. Due to the relatively small sample size, it is not possible to draw a firm conclusion. Moreover, in the stratified analysis by ethnicity, the included studies involved only Caucasians and East-Asians, and data concerning other ethnicities, such as Africans, were not found. For East-Asians, only 2 published studies were analyzed. With a small sample size such as this, the ability to find a reliable association is limited. In addition, more than 30 polymorphisms of the human VDR gene have been identified [38], but only a modest amount of these polymorphisms has been examined in CAD patients.

As a result, our meta-analysis is restricted to 4 of the most studied polymorphisms. We are unable to exclude the likelihood that other polymorphisms of the VDR gene also contribute to the risk for CAD. Even if none of these single-nucleotide polymorphisms are associated with CAD, it is possible that $V D R$, as a gene mediating the action of vitamin $\mathrm{D}$, might still play a role in CAD. Therefore, further studies are warranted to evaluate the effect of these polymorphisms on CAD risk in different ethnicities, especially in Africans and East-Asians.

The main aim of performing a meta-analysis was to increase statistical power and to obtain more compelling results by increasing the sample size. However, some limitations of the present study need to be discussed. First, because of the limited available published literature, the number of studies included in this meta-analysis was relatively small. Second, this meta-analysis focused only on papers published in the English language. Third, several studies have indicated the importance of age $[39,40]$, gene-environment interactions $[41,42]$, genegene interactions [43], and lifestyle factors [44] in CAD development. The present metaanalysis was based on crude estimates without adjusting by age, dietary vitamin D intake, and sun exposure, which is another potential limitation of our study. Fourth, statistically significant heterogeneity was observed for the BsmI and FokI polymorphisms when all the eligible studies were pooled. This heterogeneity can be due to genetic background, sample size, and the uniformity of cases and controls. After a stratified analysis by ethnicity, it was observed that the heterogeneity remarkably decreased in Caucasians, indicating that genetic background might be the source of heterogeneity.

In summary, the current meta-analysis provides pooled results of the available evidence for the association between the VDR polymorphisms and CAD risk. This gene-based analysis indicates that, based on current evidence from published studies, the ApaI, FokI, TaqI, and $B s m I$ polymorphisms of the VDR gene are not associated with CAD. Because of the paucity of the available data, additional large well-designed epidemiological studies are required to allow a more definitive conclusion. In addition, further studies should assess the influence of other VDR polymorphisms on CAD. Such studies should also take environmental factors into account, so as to gain a better and more comprehensive understanding of the relationship between VDR gene polymorphisms and CAD susceptibility. 


\section{Nutrigenetics Nutrigenomics}

\begin{tabular}{l|l}
\hline J Nutrigenet Nutrigenomics 2017;10:9-18 \\
\hline DOI: 10.1159/000455914 & $\begin{array}{l}\text { C 2017 S. Karger AG, Basel } \\
\text { www.karger.com/jnn }\end{array}$ \\
\hline
\end{tabular}

Alizadeh et al.: Common Variants of Vitamin D Receptor Gene Polymorphisms and Susceptibility to Coronary Artery Disease: A Systematic Review and Meta-Analysis

\section{Disclosure Statement}

There are no conflicts of interest to declare.

\section{Funding Sources}

There were no funding sources.

\section{References}

1 Ezzat H, et al: Prevalence of thrombophilic gene polymorphisms (FVL G1691A and MTHFR C677T) in patients with myocardial infarction. Egypt J Med Hum Genet 2014;15:113-123.

2 Miyabe $\mathrm{M}$, et al: Muscle-derived follistatin-like 1 functions to reduce neointimal formation after vascular injury. Cardiovasc Res 2014;103:111-120.

3 Gilbert, K, et al: Metabolites derived from omega-3 polyunsaturated fatty acids are important for cardioprotection. Eur J Pharmacol 2015;769:147-153.

4 Uçar F, et al: MTHFR C677T polymorphism and its relationship to myocardial infarction in the Eastern Black Sea region of Turkey. Arch Med Res 2011;42:709-712.

5 Dogra RK, et al: Prothrombotic gene polymorphisms and plasma factors in young north Indian survivors of acute myocardial infarction. J Thromb Thrombolysis 2012;34:276-282.

6 Szabó GV, Kunstár A, Acsády G: Methylentetrahydrofolate reductase and nitric oxide synthase polymorphism in patients with atherosclerosis and diabetes. Pathol Oncol Res 2009;15:631-637.

7 Onrat ST, et al: Prevalence of myocardial infarction polymorphisms in Afyonkarahisar, Western Turkey. Mol Biol Rep 2012;39:9257-9264.

8 Isordia-Salas I, etal: C677T polymorphism of the 5,10 MTHFRgene in young Mexican subjects with ST-elevation myocardial infarction. Arch Med Res 2010;41:246-250.

9 Prabhakar P, et al: Genetic variants of vitamin D receptor and susceptibility to ischemic stroke. Biochem Biophys Res Commun 2015;456:631-636.

10 Wang L, et al: Circulating 25-hydroxy-vitamin D and risk of cardiovascular disease: a meta-analysis of prospective studies. Circ Cardiovasc Qual Outcomes 2012;5:819-829.

11 Zmuda JM, Cauley JA, Ferrell RE: Molecular epidemiology of vitamin D receptor gene variants. Epidemiol Rev 2000;22:203-217.

12 Vélayoudom-Céphise F-L, et al: Vitamin D deficiency, vitamin D receptor gene polymorphisms and cardiovascular risk factors in Caribbean patients with type 2 diabetes. Diabetes Metab 2011;37:540-545.

13 Dorsch MP, et al: Vitamin D receptor genetics on extracellular matrix biomarkers and hemodynamics in systolic heart failure. J Cardiovasc Pharmacol Ther 2014;19:439-445.

14 Sygitowicz G, Pera L, Sitkiewicz D: Vitamin D receptor (VDR) polymorphism and the risk of cardiovascular events (in Polish). Kardiol Pol 2014;72:64-66.

15 Barakat K, Hitman GA: The emerging role of vitamin D and its receptor in the pathogenesis of acute coronary syndromes. Br J Cardiol 2006;13:9-12.

16 Wells G, Shea B, O'Connell D, et al: The Newcastle-Ottawa Scale (NOS) for assessing the quality of nonrandomised studies in meta-analyses. 2000. http://www.ohri.ca/programs/clinical_epidemiology/oxford.asp.

17 Zhang YG, et al: The I/D polymorphism of angiotensin-converting enzyme gene and asthma risk: a metaanalysis. Allergy 2011;66:197-205.

18 Woolf B: On estimating the relation between blood group and disease. Ann Hum Genet 1955;19:251-253.

19 Higgins JP, et al: Measuring inconsistency in meta-analyses. BMJ 2003;327:557-560.

20 Lau J, Ioannidis JP, Schmid CH: Quantitative synthesis in systematic reviews. Ann Intern Med 1997;127:820826.

21 Mantel N, Haenszel W: Statistical aspects of the analysis of data from retrospective studies. J Natl Cancer Inst 1959;22:719-748.

22 DerSimonian R, Laird N: Meta-analysis in clinical trials. Control Clin Trials 1986;7:177-188.

23 Egger M, Davey Smith G, Schneider M, Minder C: Bias in meta-analysis detected by a simple, graphical test. BM] 1997;315:629-634.

24 Ortlepp J, et al: The vitamin D receptor gene variant is associated with the prevalence of type 2 diabetes mellitus and coronary artery disease. Diabet Med 2001;18:842-845.

25 Ortlepp J, et al: Vitamin D receptor gene polymorphism BsmI is not associated with the prevalence and severity of CAD in a large-scale angiographic cohort of 3,441 patients. Eur J Clin Invest 2003;33:106-109.

26 Hossein-Nezhad A, Eshaghi SM, Maghbooli Z, et al: The role of vitamin D deficiency and vitamin D receptor genotypes on the degree of collateralization in patients with suspected coronary artery disease. Biomed Res Int 2014;2014:304250. 
27 O'Halloran A, et al: The impact on coronary artery disease of common polymorphisms known to modulate responses to pathogens. Ann Hum Genet 2006;70:934-945.

28 He L, Wang M: Association of vitamin D receptor-a gene polymorphisms with coronary heart disease in Han Chinese. Int J Clin Exp Med 2015;8:6224-6229.

29 Garbuzova VY, et al: Association of allelic polymorphisms of the Matrix Gla-protein system genes with acute coronary syndrome in the Ukrainian population. Biopolym Cell 2015;31:46-56.

30 Abu el Maaty MA, et al: Vitamin D receptor gene polymorphisms (TaqI and ApaI) in relation to 25-hydroxyvitamin D levels and coronary artery disease incidence. J Recept Signal Transduct Res 2015;35:391-395.

31 Pan X-M, et al: No association between vitamin D receptor polymorphisms and coronary artery disease in a Chinese population. DNA Cell Biol 2009;28:521-525.

32 Abu el Maaty MA, Hassanein SI, Gad MZ: Genetic variation in vitamin D receptor gene (Fok1:rs2228570) is associated with risk of coronary artery disease. Biomarkers 2016;21:68-72.

33 Zhang J, et al: Polymorphisms in the vitamin D receptor gene and type 1 diabetes mellitus risk: an update by meta-analysis. Mol Cell Endocrinol 2012;355:135-142.

34 Brøndum-Jacobsen P, Benn M, Afzal S, Nordestgaard BG: No evidence that genetically reduced 25-hydroxyvitamin D is associated with increased risk of ischaemic heart disease or myocardial infarction: a Mendelian randomization study. Int J Epidemiol 2015;44:651-661.

35 Ortlepp JR, et al: Additive effects of the chemokine receptor 2, vitamin D receptor, interleukin-6 polymorphisms and cardiovascular risk factors on the prevalence of myocardial infarction in patients below 65 years. Int J Cardiol 2005;105:90-95.

36 Van Schooten FJ, Hirvonen A, Maas LM, et al: Putative susceptibility markers of coronary artery disease: association between VDR genotype, smoking, and aromatic DNA adduct levels in human right atrial tissue. FASEB J 1998;12:1409-1417.

37 Ferrarezi D, et al: Allelic variations of the vitamin D receptor $(V D R)$ gene are associated with increased risk of coronary artery disease in type 2 diabetics: the DIABHYCAR prospective study. Diabetes Metab 2013;39: 263-270.

38 Davis CD: Vitamin D and cancer: current dilemmas and future research needs. Am J Clin Nutr 2008;88:565S569S.

39 Wei K, et al: Developmental origin of age-related coronary artery disease. Cardiovasc Res 2015;107:287-294.

40 Khan HU, et al: Coronary artery disease pattern: a comparison among different age groups. J Ayub Med Coil Abbottabad 2014;26:466-469.

41 Talmud PJ, Hawe E, Miller GJ: Analysis of gene-environment interaction in coronary artery disease: lipoprotein lipase and smoking as examples. Ital Heart J 2002;3:6-9.

42 Humphries SE, Donati MB: Analysis of gene-environment interaction in coronary artery disease. Ital Heart J 2002;3:3-5.

43 Musameh MD, et al: Analysis of gene-gene interactions among common variants in candidate cardiovascular genes in coronary artery disease. PLoS One 2015;10:e0117684.

44 Vaccarino V, et al: Sex differences in mental stress-induced myocardial ischemia in young survivors of an acute myocardial infarction. Psychosom Med 2014;76:171. 